\title{
The Relation between Postvoid Residual and Occurrence of Urinary Tract Infection after Stroke in Rehabilitation Unit
}

\author{
Bo-Ram Kim, M.D., Jeong Hoon Lim, M.D. ', Seung Ah Lee, M.D., Jin-Hyun Kim, M.D., Seong-Eun Koh, M.D., \\ Ph.D., In-Sik Lee, M.D., Ph.D., Heeyoune Jung, M.D., Jongmin Lee, M.D., Ph.D.
}

Department of Rehabilitation Medicine, Konkuk University Medical Center and School of Medicine, Seoul 143-729, Korea

${ }^{1}$ Department of Rehabilitation Medicine, Division of Neurology, National University Health System, Singapore

Objective To determine the relation between postvoid residual (PVR) and the occurrence of urinary tract infection (UTI) in stroke patients.

Method One hundred and eighty-eight stroke patients who were admitted to an inpatient rehabilitation unit and who did not have UTI on admission (105 males, 83 females, mean age 67.1 years) were included in this study. The PVR was measured 3 times within 72 hours after admission. Mean PVR, demographic variables, K-MMSE (Korean Mini-Mental State Examination), initial K-MBI (Korean Modified Barthel Index), Foley catheter indwelling time and stroke type were defined and the relation to the occurrence of UTI was analyzed.

Results UTI occurred in 74 patients $(39.4 \%)$ during admission to the rehabilitation unit. There were significant differences between the UTI and non-UTI groups in K-MMSE, K-MBI, Foley catheter indwelling time $(\mathrm{p}<0.01)$. However, age, gender, stroke location and type were not associated. The occurrence of UTI was 4.87 times higher in the patients with a mean PVR over $100 \mathrm{ml}$ than in those with a mean PVR $<100 \mathrm{ml}$. The mean PVR was $106.5 \mathrm{ml}$ in the UTI group, while it was $62.7 \mathrm{ml}$ in the non-UTI group $(\mathrm{p}<0.01)$. PVR was not associated with age.

Conclusion The UTI rate is higher when the mean PVR is over $100 \mathrm{ml}$ irrespective of gender and age. Close monitoring of PVR and appropriate intervention is needed to reduce the occurrence of UTI in stroke patients.

Key Words Urinary tract infection, Postvoid residual, Stroke

Received August 3, 2011; Accepted March 27, 2012

Corresponding author: Jongmin Lee

Department of Rehabilitation Medicine, Konkuk University Medical Center, 4-12, Hwayang-dong, Gwangjin-gu, Seoul 143-729, Korea

Tel: +82-2-2030-5351, Fax: +82-2-2030-5379, E-mail: leej@kuh.ac.kr () This is an open-access article distributed under the terms of the Creative Commons Attribution Non-Commercial License (http:// creativecommons.org/licenses/by-nc/3.0) which permits unrestricted noncommercial use, distribution, and reproduction in any medium, provided the original work is properly cited.

Copyright $\odot 2012$ by Korean Academy of Rehabilitation Medicine

\section{INTRODUCTION}

In stroke patients, increased postvoid residual (PVR) occurs commonly $^{1,2}$ and it is known to be a risk factor for urinary incontinence ${ }^{3,4}$ and urinary tract infection (UTI). ${ }^{2}$ Hung et al. reported that UTI is the second most common complication in stroke patients (13.6\%) following musculoskeletal pain $(15.0 \%) .{ }^{5}$ Roth et al. reported that $30 \%$ of the patients in their study who were receiving inpatient rehabilitation treatment for acute stroke devel- 
oped UTI. ${ }^{6}$ Dromerick also reported that the morbidity of UTI was the highest (44\%) out of all the complications in stroke survivors. Failure to manage early UTI may lead to pyelonephritis, hydronephrosis, ureter stone, and chronic renal failure, resulting in prolonged hospitalization and social and financial losses. UTI prevention is very important in stroke patients, ${ }^{8,9}$ and this study aimed to contribute to UTI prevention by identifying the risk factors of UTI and the differences in the occurrence rate of UTI according to the PVR and the patients' sex and age.

\section{MATERIALS AND METHODS}

\section{Subjects}

Of the 510 stroke patients who had been admitted to the rehabilitation unit of a university hospital in seoul within the period of August 2005 to June 2008, and who had received comprehensive rehabilitation treatment, 188 were included in this study, and those who had a history of surgery of the urinary system, who had been diagnosed with diabetes and Parkinson's disease, who had been taking autonomic-nervous-system drugs, or who had been taking antibiotics at the time of admission or transfer to the rehabilitation unit were excluded. All the patients in this study can self void at the time of admission to the rehabilitation unit (male: $\mathrm{n}=105$; female: $\mathrm{n}=83$; mean age: 67.1 years).

\section{Methods}

This was a medical-recordbased based retrospective study on stroke patients who had received comprehensive inpatient rehabilitation treatment. For all the patients in this study who had been admitted to the rehabilitation unit, the PVR was measured, using a bladder scanner Biocon-500 ${ }^{\mathrm{TM}}$ (Mcube Technology, Seoul, Korea), once daily for the first 72 hours (total of three times) after admission or transfer to the rehabilitation unit. The measurement was performed by skillful nurses from the rehabilitation unit. The measurement data were recorded on the medical chart, and the mean measurements were compared. For the urine test, the midstream urine was collected, and if a patient could not express his/her voiding sense due to decreased cognitive function, urine was collected using the aseptic catheterization. A routine urine test was performed once a week from the time of admission or transfer to the rehabilitation unit to the time of discharge therefrom, and additional tests were performed if symptoms suggestive of UTI developed during the week. In addition, a urine culture test was performed at the time of admission or transfer to the rehabilitation unit and when symptoms and signs of UTI were observed. In the present study, UTI was defined as (i) the presence of fever and of symptoms of UTI (urodynia, urinary frequency, and urinary urgency) and (ii) the presence of bacteriuria $\left(>10^{5} / \mathrm{ml}\right.$ or $>10^{3} / \mathrm{ml}$ bacterial count) and pyuria $\left(>10 / \mathrm{mm}^{3}\right.$ white blood cell count). ${ }^{9,10}$ The urine volume was measured; and a urinary test as well as the Korean Mini-Mental State Examination (K-MMSE) and Korean-Modified Barthel Index (K-MBI) were performed. The number of days from the onset of the stroke to the admission to the rehabilitation unit, and the number of days of Foley catheter indwelling since the onset of stroke were examined. The stroke types and locations were classified according to the data obtained from the brain computed tomography and magnetic resonance imaging performed during the acute phase of the stroke.

Considering prostatic hypertrophy in the male patients and menopause in the female patients, the PVRs of the patients aged $\geq 50$ years were compared with those of the patients aged $\leq 50$ years, and for statistical analysis, SPSS ver. 17 for Windows was used. The Mann-Whitney test was used to assess the statistical significance of the following: the difference in PVR between the UTI and nonUTI groups; the difference in PVR between the UTI and non-UTI groups according to sex and age; the number of days from the onset of stroke to admission to the rehabilitation unit; and the number of days of Foley catheter indwelling since the onset of stroke. The difference in stroke type and location between the two groups was assessed via chi-square test $(\mathrm{p}<0.05)$.

\section{RESULTS}

\section{General characteristics}

Of the total of 188 patients, 105 were male and $83 \mathrm{fe}$ male, with a mean age of $67.1 \pm 13.3$. The numbers of male patients in the UTI and non-UTI groups were 41 and 64, respectively, and the numbers of female patients in the UTI and non-UTI groups were 33 and 50, respectively. The proportions of the patients with lesions in the anterior cerebral artery in the UTI and non-UTI groups were 8.1 and $7.9 \%$, respectively; in the middle cerebral artery, 
56.8 and 59.6\%; in the posterior cerebral artery, 5.4 and $5.3 \%$; and in the brainstem, 13.5 and $22.8 \%$. There was thus no significant difference in the locations of the lesions between the two groups. For the stroke types, the proportions of the patients with ischemic stroke in the UTI and non-UTI groups were 43.2 and $89.5 \%$, respectively, and those of the patients with hemorrhagic stroke were 56.8 and $10.5 \%$. There was thus no significant difference between the two groups (Table 1). The PVR and K-MMSE scores, the initial K-MBI scores at the time of admission to the rehabilitation unit, and the Foley catheter indwelling time, however, were significantly different between the two groups $(\mathrm{p}<0.01)$ (Table 1$)$. In particular, multivariate regression analysis showed that the initial $\mathrm{K}$ -
MBI scores at the time of admission to the rehabilitation unit influenced the onset of UTI (Table 2).

\section{UTI occurence comparison according to the PVR}

For $\geq 100$ and $<100 \mathrm{ml}$ PVR, the likelihoods of the onset of UTI were $31 \%$ and $68 \%$, respectively (odds ratio: 4.87 ) (Table 3).

\section{PVR comparison according to the onset of UTI}

The mean PVR was higher in the UTI group (106.5 \pm 102.0 $\mathrm{ml})$ than in the non-UTI group $(106.5 \pm 102.0 \mathrm{ml})(\mathrm{p}<0.01)$ (Table 1). The mean PVRs in the female patients $(n=83)$ in the UTI and non-UTI groups were 97.0 \pm 77.4 and $69.1 \pm 114.2 \mathrm{ml}(\mathrm{p}<0.01)$, respectively, and in the male

Table 1. Profile of Study Population Admitted to Rehabilitation Unit (N=188)

\begin{tabular}{|c|c|c|c|}
\hline Variable & Total $(\mathrm{N}=188)$ & UTI $(N=74)$ & Non-UTI $(\mathrm{N}=114)$ \\
\hline Age (years) & $67.1( \pm 13.3)$ & $67.3( \pm 13.3)$ & $66.8( \pm 13.5)$ \\
\hline \multicolumn{4}{|l|}{ Sex } \\
\hline Female & $83(44 \%)$ & $33(44.6 \%)$ & $50(43.9 \%)$ \\
\hline Male & $105(56 \%)$ & $41(55.4 \%)$ & $64(56.1 \%)$ \\
\hline \multicolumn{4}{|l|}{$\operatorname{PVR}(\mathrm{ml}) *$} \\
\hline Mean \pm SD & $74.2( \pm 95.2)$ & $106.5( \pm 102.0)$ & $62.7( \pm 88.9)$ \\
\hline Median (range) & $36.7(0-601)$ & $85.0(0-601)$ & $26.8(0-582)$ \\
\hline Onset to admission day & $131.5( \pm 666.6)$ & $94.7( \pm 153.4)$ & $155.4( \pm 847.7)$ \\
\hline K-MMSE* & $15.6( \pm 10.4)$ & $10.7( \pm 10.5)$ & $18.8( \pm 9.1)$ \\
\hline Initial K-MBI score* & $33.9( \pm 30.9)$ & $18.3( \pm 25.5)$ & $44.0( \pm 30.0)$ \\
\hline Foley catheter indwelling time (days)* & $5.6( \pm 15.1)$ & $12.8( \pm 18.1)$ & $4.18( \pm 11.7)$ \\
\hline \multicolumn{4}{|l|}{ Stroke side } \\
\hline Rt & $75(39.9 \%)$ & $18(24.3 \%)$ & $57(50 \%)$ \\
\hline Lt & $74(39.4 \%)$ & $35(47.3 \%)$ & $39(34.2 \%)$ \\
\hline Bilateral & $39(20.7 \%)$ & $21(28.4 \%)$ & $18(15.8 \%)$ \\
\hline \multicolumn{4}{|l|}{ Stroke type } \\
\hline Ischemic & $134(71.3 \%)$ & $32(43.2 \%)$ & $102(89.5 \%)$ \\
\hline Hemorrhagic & $54(28.7 \%)$ & $42(56.8 \%)$ & $12(10.5 \%)$ \\
\hline \multicolumn{4}{|l|}{ Stroke lesion } \\
\hline ACA territory & $15(8 \%)$ & $6(8.1 \%)$ & $9(7.9 \%)$ \\
\hline MCA territory & $110(58.5 \%)$ & $42(56.8 \%)$ & $68(59.6 \%)$ \\
\hline PCA territory & $10(5.3 \%)$ & $4(5.4 \%)$ & $6(5.3 \%)$ \\
\hline Brainstem & $36(19.1 \%)$ & $10(13.5 \%)$ & $26(22.8 \%)$ \\
\hline SAH & $17(9 \%)$ & $12(16.2 \%)$ & $5(4.4 \%)$ \\
\hline
\end{tabular}

Values are mean \pm SD or $\mathrm{n}(\%)$, unless otherwise indicated

UTI: Urinary tract infection, PVR: Postvoid residual, SD: Standard deviation, K-MMSE: Mini-Mental State Examination (Korean), K-MBI: Modified Barthel Index (Korean), ACA: Anterior cerebral artery, MCA: Middle cerebral artery, PCA: Posterior cerebral artery, SAH: Subarachnoid hemorrhage ${ }^{*} \mathrm{p}<0.01$ 
patients ( $\mathrm{n}=105), 114.2 \pm 118.5$ and $41.4 \pm 50.4 \mathrm{ml}(\mathrm{p}<0.01)$. Thus, the mean PVRs were higher in the UTI group than in the non-UTI group for both the female and male patients (Fig. 1). For the patients aged $<50$ years $(n=31)$, the mean PVRs in the UTI and non-UTI groups were $138.0 \pm 174.6$ and $33.9 \pm 69.3 \mathrm{ml}$, respectively, and for the patients aged $\geq 50$ years $(\mathrm{n}=157), 100.5 \pm 81.9 \mathrm{ml}(\mathrm{p}<0.05)$ and $62.8 \pm 90.2 \mathrm{ml}(\mathrm{p}<0.01)$. Thus, the mean PVR was significantly higher in the UTI group than in the non-UTI group irrespective of the patient's age (Fig. 2).

\section{DISCUSSION}

It is known that the incidence of UTI increases in patients with spinal cord injury, ${ }^{11}$ diabetes, ${ }^{12}$ and increased PVR. ${ }^{8,13-16}$ However, the specific data regarding the difference in UTI incidence rate in stroke patients according to the PVR volume, or patients' demographics are limited.

The studies on 188 patients who received inpatient treatment for stroke, reported the incidence rate of UTI

Table 2. Risk Factors of UTI

\begin{tabular}{lcc}
\hline & Significance & OR (95\% CI) \\
\hline Age decade & 0.270 & $0.975(0.933-1.019)$ \\
Sex & 0.774 & $1.143(0.460-2.840)$ \\
Postvoid residual & 0.563 & $1.001(0.997-1.006)$ \\
K-MMSE & 0.165 & $0.958(0.903-1.018)$ \\
K-MBI* & 0.037 & $0.974(0.951-0.998)$ \\
$\begin{array}{l}\text { Foley catheter } \\
\text { indwelling time }\end{array}$ & 0.400 & $1.016(0.979-1.055)$ \\
\hline
\end{tabular}

OR: Odds ratio, CI: Confidence interval

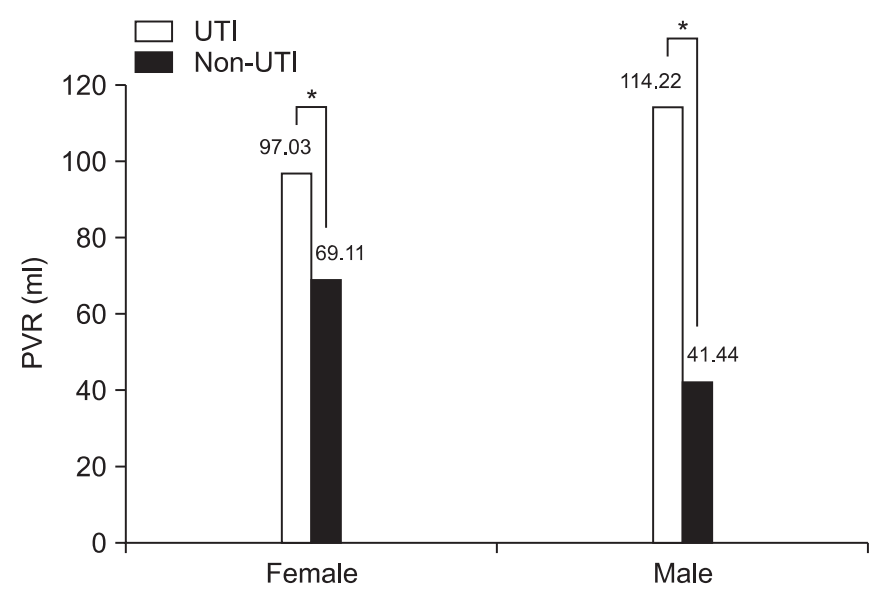

Fig. 1. Comparison with PVR volume and incidence of UTI according to sex. ${ }^{*} \mathrm{p}<0.01$ by Mann-Whitney test. was high (39.4\%), ${ }^{6,7}$ Increased PVR observed in patients with diabetic cystopathy may be caused by the decrease of urinary bladder sensation and urinary bladder muscle contractility. ${ }^{17}$ Among the various drugs that influence urinary retention, anticholinergic agents result in urinary retention by decreasing the contractility of the urinary bladder; alpha receptor agonists may cause urinary retention by contracting the urethral sphincter, particularly in male patients with prostatic hypertrophy; ${ }^{18}$ and beta blockers increase the morbidity of UTI by interrupting the contraction of the detrusor and causing consequential urinary retention, although the relation between beta blockers and UTI in stroke patients has not yet been clearly identified. ${ }^{1}$ On account of this, the analysis in the present study excluded patients with diabetes and those who had been taking anticholinergic agents and beta blockers.

In the present study, PVRs were classified using $100 \mathrm{ml}$ as the criterion, based on the balanced-bladder concept (i.e., the PVR is less than $20 \%$ of the normal bladder volume), ${ }^{19}$ and on numerous studies stating that the PVR required for the intermittent catheterization was 100 $150 \mathrm{ml}$ or more, ${ }^{1,20}$ although there is no established criterion for adequate bladder emptying. It was shown in

Table 3. Incidence of UTI by Admission PVR Volume

\begin{tabular}{lcc}
\hline & UTI $(\mathbf{n}=74)$ & Non-UTI $(\mathbf{n}=114)$ \\
\hline PVR $<100 \mathrm{ml}(\mathrm{n}=144)^{*}$ & $44(30.6 \%)$ & $100(69.4 \%)$ \\
PVR $\geq 100 \mathrm{ml}(\mathrm{n}=44)^{*}$ & $30(68.2 \%)$ & $14(31.8 \%)$ \\
\hline
\end{tabular}

Odds ratio: 4.87

${ }^{*} \mathrm{p}<0.05$ by $\chi^{2}$ test

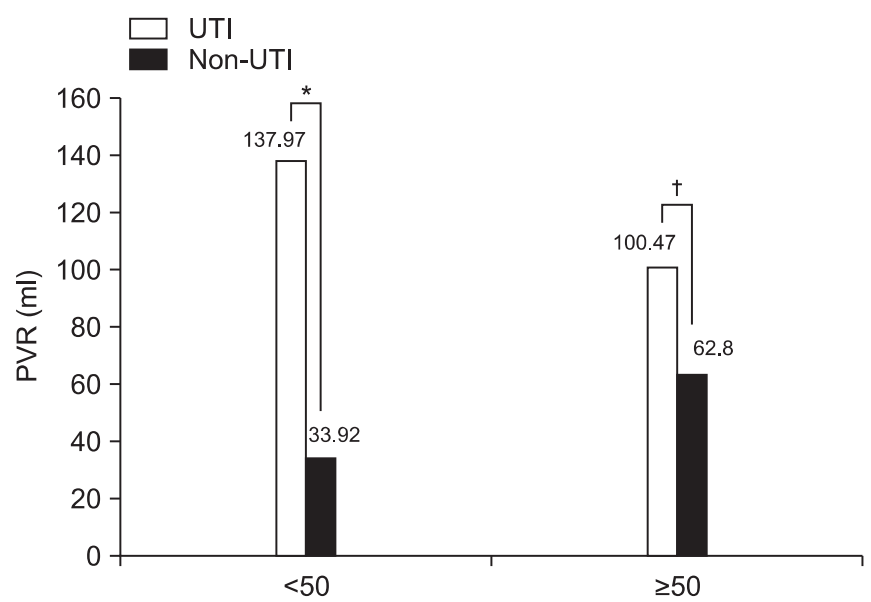

Fig. 2. Comparison of PVR volume and incidence of UTI according to age. ${ }^{*} \mathrm{p}<0.01,{ }^{\dagger} \mathrm{p}<0.05$ by Mann-Whitney test. 
this study that the likelihood of developing UTI was 4.87 times higher with a PVR of $100 \mathrm{ml}$ or more than with a PVR of less than $100 \mathrm{ml}$.

To analyze the difference in mean PVR by sex and age, patients were classified into those younger than 50 years old and those aged 50 years or older. This is because studies reported that 42 or $75 \%$ of the male patients in such studies aged 50 years or older had lower UTI symptoms (e.g., urinary retention due to prostatic hypertrophy). ${ }^{21,22}$ and it is known that menopause starts at 50 years on average in women. In this study, the mean PVR in the UTI group was higher than that in the non-UTI group in both the patients aged 50 years or older and those younger than 50 years $(\mathrm{p}<0.05)$ In men, the prevalence of prostatic hypertrophy increases with age, and consequently, the PVR also increases. The previous studies indicated PVR increase not only in men but also in women, which is considered to be due to the decreased contractility of the detrusor in stroke. ${ }^{2,23}$ In women, however, particularly in those aged 50 years or older, menopause is another factor of increased PVR. Decreased estrogen due to menopause increases the vaginal $\mathrm{pH}$ and decreases the lactobacilli. This subsequently increases the colonization of gramnegative bacilli, resulting in an increased risk of developing UTI. ${ }^{24}$ In addition, as the vagina and urethra have the same embryonic origin, estrogen receptors also exist in the vesical trigone and epithelium of the urethra. ${ }^{24} \mathrm{~A}$ study reported that oral estrogen in elderly women would decrease the PVR. ${ }^{25}$ In relation with the use of estrogen, however, the possibility of an increased risk of breast cancer should be carefully considered.

Although whether the detrusor areflexia is related with the stroke lesion remains uncertain, a study reported that if stroke occurs in the superomedial region of the frontal lobe and in the genu of the corpus callosum, detrusor areflexia is likely to present as the motor area of the detrusor muscle exists in the superomedial region of the frontal lobe and in the genu of the corpus callosum, and if the cerebral cortex, internal capsule, or cerebellum is damaged, detrusor hyperreflexia may occur. ${ }^{26}$ However, Kong and Young reported that aphasia, diabetes, cognitive dysfunction, and low functional level influence urinary retention rather than the specific lesion of stroke. ${ }^{27}$ In this study the K-MMSE and K-MBI scores and the Foley catheter indwelling time were significantly different between the UTI and non-UTI groups, suggesting that a low functional level may influence the onset of UTI. As many of the patients who had urinary retention immediately after stroke recovered at the time of discharge from the rehabilitation unit, the period after the stroke may also act as a variable that can influence PVR measurements. In this context, it is considered that the cognitive function, functional level, presence of aphasia, and period after stroke should be investigated further in the future studies.

\section{CONCLUSION}

The incidence rate of UTI in stroke patients is about $40 \%$, and factors such as low cognitive function, low functional level, high PVR, and long Foley catheter indwelling time may be risk factors for the onset of post-stroke UTI. In addition, it was shown in this study that the likelihood of developing UTI was 4.87 times higher with a PVR of $100 \mathrm{ml}$ or more, and the incidence rate of UTI was higher in the patients with a higher PVR, irrespective of sex and age.

It is believed that for the prevention of UTI in poststroke patients, PVR monitoring with the use of a bladder scanner is the most important and simplest observation method. In addition, adequate use of clean intermittent catheterization in patients with a PVR of $100 \mathrm{ml}$ or more will be helpful for the prevention of UTI, a common complication in post-stroke patients.

\section{REFERENCES}

1. Dromerick AW, Edwards DF. Relation of postvoid residual to urinary tract infection during stroke rehabilitation. Arch Phys Med Rehabil 2003; 84: 1369-1372

2. Garrett VE, Scott JA, Costich J, Aubrey DL, Gross J. Bladder emptying assessment in stroke patients. Arch Phys Med Rehabil 1989; 70: 41-43

3. Gelber DA, Good DC, Laven LJ, Verhulst SJ. Causes of urinary incontinence after acute hemispheric stroke. Stroke 1993; 24: 378-382

4. Ween JE, Alexander MP, D'Esposito M, Roberts M. Incontinence after stroke in a rehabilitation setting: outcome associations and predictive factors. Neurology 1996; 47: 659-663

5. Hung JW, Tsay TH, Chang HW, Leong CP, Lau YC. Incidence and risk factors of medical complications 
during inpatient stroke rehabilitation. Chang Gung Med J 2005; 28: 31-38

6. Roth EJ, Lovell L, Harvey RL, Heinemann AW, Semik P, Diaz S. Incidence of and risk factors for medical complications during stroke rehabilitation. Stroke 2001; 32: 523-529

7. Dromerick A, Reding M. Medical and neurological complications during inpatient stroke rehabilitation. Stroke 1994; 25: 358-361

8. Yang CY, Choi SM, Kim DY, Ko JY, Jeon PS. The trends of urinary tract infection in patients with neurogenic bladder. J Korean Acad Rehab Med 1997; 21: 689-695

9. Barnett BJ, Stephens DS. Urinary tract infection: an overview. Am J Med Sci 1997; 314: 245-249

10. Flaherty PJ, Liljestrand JS, O'Brien TF. Urinary tract infections in an American rehabilitation hospital. J Hosp Infect 1984; 5: 75-80

11. Cardenas DD, Hooton TM. Urinary tract infection in persons with spinal cord injury. ArchPhys Med Rehabil 1995; 76: 272-280

12. Hampson SJ, Noble JG, Rickards D, Milroy EJ. Does residual urine predispose to urinary tract infection? Br J Urol 1992; 70: 506-508

13. Kim SH, Chong SY, Chung JS, Choi YC. Effect of postures on residual urine following catheterization in spinal cord injured patients. J Korean Acad Rehab Med 1997; 21: 493-499

14. Lukacz ES, DuHamel E, Menefee SA, Luber KM. Elevated postvoid residual in women with pelvic floor disorders: prevalence and associated risk factors. Int Urogynecol J Pelvic Floor Dysfunct 2007; 18: 397-400

15. Merritt JL. Residual urine volume: correlate of urinary tract infection in patients with spinal cord injury. Arch Phys Med Rehabil 1981; 62: 558-561

16. Griffiths DJ, Harrison G, Moore K, McCracken P. Variability of post-void residual urine volume in the elderly. Urol Res 1996; 24: 23-26
17. Brown JS. Diabetic cystopathy--what does it mean? J Urol 2009; 181: 13-14

18. Drake MJ, Nixon PM, Crew JP. Drug-induced bladder and urinary disorders. Incidence, prevention and management. Drug Saf 1998; 19: 45-55

19. Dania D. Management of bladder dysfunction. In:Braddom RL, editor. Physical medicine and rehabilitation, 3rd ed, Philadelphia: Saunders, 2007

20. Knapp PM Jr. Identifying and treating urinary incontinence. The crucial role of the primary care physician. Postgrad Med 1998; 103: 279-280

21. Da Silva FC. Benign prostatic hyperplasia: natural evolution versus medical treatment. Eur Urol 1997; 32 Suppl 2: 34-37

22. Naslund MJ, Gilsenan AW, Midkiff KD, Bown A, Wolford ET, Wang J. Prevalence of lower urinary tract symptoms and prostate enlargement in the primary care setting. Int J Clin Pract 2007; 61: 1437-1445

23. Hershkovitz A, Beloosesky Y, Pomp N, Brill S. Is routine screening for urinary tract infection in rehabilitation day-hospital elderly patients necessary? Arch Gerontol Geriatr 2002; 34: 29-36

24. Marshburn PB, Carr BR. Hormone replacement therapy. Protection against the consequences of menopause. Postgrad Med 1992; 92: 145-148

25. Stern JA, Hsieh YC, Schaeffer AJ. Residual urine in an elderly female population: novel implications for oral estrogen replacement and impact on recurrent urinary tract infection. J Urol 2004; 171: 768-770

26. Burney TL, Senapati M, Desai S, Choudhary ST, Badlani GH. Acute cerebrovascular accident and lower urinary tract dysfunction: a prospective correlation of the site of brain injury with urodynamic findings. J Urol 1996; 156: 1748-1750

27. Kong KH, Young S. Incidence and outcome of poststroke urinary retention: a prospective study. Arch Phys Med Rehabil 2000; 81: 1464-1467 